\title{
A COMPARISON OF THE INSTABILITIES AT THE NIVEA AND PALLIDA LOCI IN ANTIRRHINUM MAJUS
}

\author{
BRIAN J. HARRISON and ROSEMARY CARPENTER \\ The John Innes Institute, Colney Lone, Norwich, NOR, 7OF
}

Received 20.xi.72

\begin{abstract}
SUMMARY
The unstable recurrens alleles of nivea and pallida have been compared for sensitivity to temperature during development. Previous work showed that the palrec allele mutates germinally and somatically with a greater frequency at $15^{\circ}$ than at $25^{\circ} \mathrm{C}$. The nivrec allele is less sensitive to temperature but somatic instability is still inversely correlated with temperature. There is no difference in germinal instability at the two temperatures for nivrec.

The genetic stabiliser controls for palrec and nivrec are independent.

Chemical mutagens and X-rays are ineffective in inducing changes in instability of either allele.

Plants doubly homozygous for the two rec alleles and for the aurone producing sulfurea gene show that nivrec usually mutates prior to palrec; instances of palrec mutating first have possibly been seen but the flush that frequently occurs in plants homozygous for nivrec prevents a definite conclusion as to whether there is an obligate mutational sequence.

An example of paramutation is described. Results vary according to the temperature at the time of the cross and during seed maturation, and depend on the direction of the cross; paramutagenic female parents induce a higher frequency of paramutants.

Lines of varying paramutability and paramutagenicity have been established.

Somatic paramutation in homozygous nivrec regularly occurs and varies with plant development.
\end{abstract}

\section{INTRODUCTION}

THE unstable allele recurrens at the pallida locus in Antirrhinum majus has previously been investigated (Harrison and Fincham, 1964, 1968; Fincham and Harrison, 1967). The pertinent points elucidated in this work were: (a) the inverse correlation of temperature during flower development with the frequency of both gametic and somatic mutations of pallida-recurrens (pal rec) to $\mathrm{Pallida}^{+}\left(\mathrm{Pal}^{+}\right) ;(\mathrm{b})$ the existence of an array of stable and unstable alleles derived from the unstable palrec; (c) the influence of an unlinked stabiliser system upon the degree of instability. The palrec allele, if unmutated and homozygous, prevents the formation of anthocyanin but permits the synthesis of aurone and flavones; thus corolla lobes are unpigmented but the face area is yellow. When the highly unstable pal rec allele mutates, either somatically or germinally, it most frequently mutates to $\mathrm{Pal}^{+}$, which allows full expression of anthocyanin pigment.

The instability phenomenon, usually identified by the presence of pigment in distinct flakes, has been described in a range of material (Nicotiana, maize, Portulaca, Delphinium and Primula; refs. in Harrison and Fincham, 1964). However, no previous account describes a situation in which more than one unstable gene affects the expression of pigment in the same parts of 
the organism. In Antirrhinum majus a comparison has been made between the behaviour of palree and another highly mutable allele at the unlinked locus nivea (niv). The nivea-recurrens (niv rec) allele mutates to produce pigment similarly to palrec but in the unmutated form the corolla is albino. While the yellow aurone face area in the unstable palrec flower is fully pigmented, in one homozygous for niv rec the face areas exhibit yellow flakes of aurone; these indicate mutations to $\mathrm{Nivea}^{+}\left(\mathrm{Niv}^{+}\right)$and the consequent production of the aurone pigment. Flakes of anthocyanin pigment are seen on the remainder of the corolla.

If the two alleles, palrec and nivrec, are incorporated homozygously in the same plant, anthocyanin is produced only in the corolla lobe tissue where coincident somatic mutations of both unstable alleles have occurred; the frequency of magenta flakes in consequence is greatly reduced. In the face area, aurone synthesis is prevented solely by unmutated niv rec and the frequency of yellow mutant flakes reflects mutation of niv rec alone (Harrison, 1971).

In the present paper a comparison of the two unstable alleles is made and some additional data on the doubly homozygous unstable plants are discussed.

The concept of paramutation based on the non-Mendelian segregation derived from certain heterozygotes has been analysed and exemplified by Brink (1958) for the $R$ locus in maize. In the cross $r^{\sigma} r^{\sigma} \times R^{r} R^{r}$ all the kernels are darkly mottled; in $r^{0} r^{0} \times R^{s t} R^{s t}$ all the kernels are stippled; but in the cross $r^{0} r^{0} \times R^{r} R^{s t}$ half the kernels are stippled, as expected, while the other half is unexpectedly only weakly pigmented. It is postulated that the $R^{r}$ allele has been altered in some way (paramutated) by its association with $R^{s t}$ (the paramutagenic allele). The paramutant form occurs invariably in the $F_{1}$ and persists through several generations but subsequently tends to revert to the standard phenotype. More recently, Brink, Styles and Axtell (1968) state that paramutation is an intrinsic property of certain alleles and that paramutagenic factors only exert an influence on the susceptible paramutable allele; they do not instigate paramutation but act as a stimulant to a process that can occur independently of it. A comparison of the paramutable behaviour at the $r$ locus in maize is made here with niv rec in the sense that a predictable alteration in the expression of a gene occurs in certain heterozygotes through association with alleles of different origin and that reversion of the weakly pigmented paramutant form may subsequently occur. As an extension to the general concept of paramutation it is suggested that susceptible nivec alleles when homozygous can paramutate somatically; the possible stimulation for such a change could come from the changing internal environment of the developing or aging plant. The niv rec plant may thus have two main somatic "mutational" pathways: the frequent mutation from nivrec to the full-red $\mathrm{Niv}^{+}$(which can also occur gametically) and, conjecturally, mutation to the weakly pigmented paramutant form that invariably occurs sometime during plant development.

\section{Materials AND Methods}

\section{(a) Antirrhinum stocks}

The origins of the pallida stocks are described by Harrison and Fincham (1964). 
The nivrec stock was obtained from Dr H. Böhme, Institut für Kulturpflanzenforschung, Gatersleben, Germany (D.D.R.). Originally this stock carried the gene Eluta which dilutes and spatially restricts the expression of pigment. In the present studies niv rec has been combined with homozygous eluta to allow a full expression of pigment, comparable, in this respect, with that in the palrec material, and inbred by selfing for six generations.

The nivea lines used are: (a) one marketed under the name of "Snowman" by Messrs Suttons, Reading, and inbred here for three generations prior to its first use; (b) a line sent by $\mathrm{Dr}$ R. Maly, Max Planck Institute, Tübingen, in 1955 and subsequently kept as an inbred stock for 10 generations; a reconstituted Tübingen nivea, now containing eluta, replaces the original and was inbred for two generations prior to its first use.

\section{(b) Estimation of frequency of mutant sites}

The frequency of somatic mutation, as shown by flakes of pigment, was estimated by counting, with the aid of a dissecting microscope, all the flakes and the number of cells in each flake in a $1 \mathrm{~mm}$. wide traverse across the forward facing surface of one of the upper lobes of the corolla. The number of possible traverses was estimated together with a correction for their varying lengths to give a multiplying factor for the traverse figure and so an estimate of the total number of flakes per lobe. If the mutant sites were very few a complete count of one lobe was made. The aurone flakes were always counted on the whole face of niv ${ }^{r e c}$ flowers and not estimated.

\section{(c) Controlled Environment Cabinets}

Whenever germinal or somatic mutation frequencies were to be estimated the plants were raised in Controlled Environment Cabinets set at either $15^{\circ}$ or $25^{\circ} \mathrm{C}$. Ceiling banks of fluorescent tubes provided an illumination of $c .1000$ foot candles at the top of the growing plants for a period of 12 hours per day.

\section{Results}

\section{(a) Alleles of nivea}

The following alleles at the nivea locus have been recognised: (1) Nivea ${ }^{+}$ $\left(\mathcal{N i v}^{+}\right)$; (2) nivea-recurrens (niv $\left.{ }^{r e c}\right)$; (3) nivea-" rubra" (niv ${ }^{r u b r a)}$; (4) nivea "carnea" (niv $\left.{ }^{\text {car }}\right)$; (5) nivea (niv).

$\mathrm{Niv}^{+}$is the dominant full red allele, the heterozygote with each of the other alleles being visibly indistinguishable from the homozygote. The nivrec allele resembles niv in giving albino flowers devoid of all pigment but is highly unstable, mutating to $\mathrm{Niv}^{+}$both germinally and somatically. Germinal mutations give plants whose flowers are all deep magenta (traditionally called full red) with solid yellow face; somatic mutations give flowers flaked with sites of anthocyanin on the lobes and tube and aurone on the face or all full red with solid yellow face if the somatic mutation occurs early in flower development.

The nivrec stocks used in these experiments can also produce "flushed" flowers with a pigmented background against which the darker $\mathrm{Niv}^{+}$flakes can be seen. This may be due to a failure of nivrec when unmutated to inhibit pigment production completely or, more likely, to somatic mutation producing a state of the gene having much the same pigment producing effect as niv-carnea (see below). As will be argued below, the high frequency 
and predictability of this change suggest that it should be classed as an example of paramutation (see section $\mathrm{v}$ ).

The nivrubra is a paler full red (comparable to palrubra) and arose during the current work. A niv ${ }^{r u b r a} /$ niv $^{r e c}$ heterozygote shows $\mathcal{N i v}^{+}$flakes against the slightly paler background. Flakes of nivrubra have been seen as somatic sectors which had smaller $\mathrm{Niv}^{+}$flakes of a lower frequency than on the remainder of the corolla; this indicated that in homozygous nivec, one allele had mutated somatically to nivrubra and the remaining nivec allele was still mutating to $\mathrm{Niv}^{+}$(as only one nivec allele was present the frequency of flakes was halved) (see fig. 1).

The niv car allele (comparable to palcar) is indistinguishable from many flushed plants but is less variable in its pigment intensity. This allele arose during the course of the present work, and, when heterozygous with nivrec gives a flower with flakes against a flushed background. An unstable precursor of niv car frequently arose, mutating somatically to produce streaks of pale flush of the intensity of carnea; this unstable form soon gives way to stable nivear as the inflorescence develops.

An examination of the corolla lobes of nivrec reveals that the majority of mutant sites are to the full red $\mathrm{Niv}^{+}$. In comparison with palrec a greater number of pale sites occurs in lobes of nivrec; these may be mutations to the

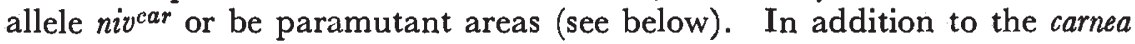
sites, somatic mutations can occur of a rubra intensity, an intensity approximately midway between $\mathcal{N i v}^{+}$and niverr. Fig. 1 shows a lobe in which there are adjacent sectors of rubra and carnea type. The darker sites of mutations to $\mathcal{N i v}{ }^{+}$are seen against the two backgrounds.

\section{(b) Effect of temperature upon the instability of nivea-recurrens}

Plants from two niv rec families of similar origin were grown at $15^{\circ}$ and $25^{\circ}$ C. The frequency of flaking was recorded throughout a flowering period of 14 weeks. The mean mutant site number of plants from the two families (M158 ${ }^{\mathrm{R}}$ and $\mathrm{M} 223$ ) was 633 at $25^{\circ} \mathrm{C}$. and 3902 at $15^{\circ} \mathrm{C}$. (table 1 ). Although an inverse correlation of site number with temperature is apparent it is not so extreme as the difference obtained with palrec (table 2).

As the somatic mutation rate of nivrec is influenced to a much lesser degree by temperature in the $15^{\circ}$ to $25^{\circ} \mathrm{C}$. range than is that of palrec it might be expected that gametic mutations of nivrec to $\mathcal{N i v}^{+}$would also be less affected. Table 3 shows that no significant difference existed for the production of gametic mutations to $\mathrm{Niv}^{+}$at $15^{\circ}$ and $25^{\circ} \mathrm{C}$. if assessed either on the number of full red progeny ( 3.4 per cent. compared with 3.7 per cent.) or of capsules containing at least one $\mathcal{N} i v^{+}$seed ( 59 per cent. compared with 47 per cent.). Although an accurate assessment of germinal mutation rate is obscured by early mutations producing more full red progeny than late mutations, it is apparent that niv rec was germinally and somatically affected much less by the temperature differential tested than was palrec. However, somatic instability for both recurrens alleles is significantly correlated inversely with temperature.

\section{(c) The flushing effect}

In table 1 a fall in the frequency of somatic mutation is recorded for plant $\mathrm{M} 158^{\mathrm{R}}$ at $25^{\circ} \mathrm{C}$.; the main effect occurred between weeks 4 and 5 . 
TABLE 1

Somatic mutation frequencies in homozygous nivrec plants, one from each of two families grown at two different temperatures

\begin{tabular}{|c|c|c|c|c|c|c|c|c|}
\hline \multirow{3}{*}{$\begin{array}{l}\text { Week of } \\
\text { flowering }\end{array}$} & \multicolumn{4}{|c|}{$25^{\circ} \mathrm{C}$. } & \multicolumn{4}{|c|}{$15^{\circ} \mathrm{C}$. } \\
\hline & \multicolumn{2}{|c|}{$\begin{array}{l}\text { Number of } \\
\text { mutant sites }\end{array}$} & \multicolumn{2}{|c|}{$\begin{array}{l}\text { Number of } \\
\text { pigmented cells }\end{array}$} & \multicolumn{2}{|c|}{$\begin{array}{l}\text { Number of } \\
\text { mutant sites }\end{array}$} & \multicolumn{2}{|c|}{$\begin{array}{l}\text { Number of } \\
\text { pigmented cells }\end{array}$} \\
\hline & $\mathrm{M} 158^{\mathrm{R}}$ & M223 & $\mathrm{M} 158^{\mathrm{R}}$ & M223 & M158R & M223 & $\mathrm{M} 158^{\mathrm{R}}$ & M223 \\
\hline 1 & 742 & - & 4,410 & - & - & - & - & - \\
\hline 2 & 1,210 & - & 5,452 & - & - & - & - & - \\
\hline 3 & 344 & 329 & 1,803 & 14,170 & 3,349 & - & 62,290 & - \\
\hline 4 & 332 & 2,129 & 1,526 & 8,224 & 2,960 & - & 55,808 & - \\
\hline 5 & 9 & 1,173 & 28 & 4,157 & 2,946 & 5,216 & 43,632 & 32,960 \\
\hline 6 & - & 1,193 & - & 2,614 & 3,057 & 5,595 & 35,449 & 32,263 \\
\hline 7 & 26 & 1,130 & 117 & 2,562 & 2,358 & 4,333 & 31,087 & 43,693 \\
\hline 8 & 14 & 562 & 322 & 1,210 & 2,731 & 3,854 & 32,331 & 36,643 \\
\hline 10 & 37 & 1,381 & 223 & 2,291 & 1,865 & 4,859 & 28,771 & 44,102 \\
\hline 11 & 26 & 636 & 80 & 1,277 & - & 5,552 & - & 37,683 \\
\hline 12 & 13 & 690 & 44 & 1,687 & 2,167 & 5,728 & 15,739 & 39,630 \\
\hline 13 & 11 & 556 & 43 & 1,484 & 1,845 & 6,699 & 28,728 & 38,776 \\
\hline 14 & - & 1,388 & - & 3,623 & 1,985 & 5,676 & 25,037 & 24,005 \\
\hline \multirow[t]{2}{*}{ Mean } & 251 & 1,015 & 1,277 & 3,936 & 2,526 & 5,279 & 35,887 & 36,639 \\
\hline & \multicolumn{2}{|c|}{633} & & & \multicolumn{2}{|c|}{$\underbrace{}_{3,902}$} & & \\
\hline
\end{tabular}

TABLE 2

Effect of temperature on the numbers of mutant sites on flowers of palrec and nivrec homozygotes

\begin{tabular}{|c|c|c|}
\hline & \multicolumn{2}{|c|}{ Growth temperature } \\
\hline & $25^{\circ} \mathrm{C}$. & $15^{\circ} \mathrm{C}$. \\
\hline Pallida-recurrens* & 15 & c. 18,000 \\
\hline Nivea-recurrenst & 633 & 3,90 \\
\hline
\end{tabular}

* From Harrison and Fincham (1964).

$\dagger$ From table 1.

TABLE 3

Comparison of gametic mutation frequencies of palrec and nivrec at two growth temperautres

\begin{tabular}{|c|c|c|c|c|c|}
\hline Genotype & $\begin{array}{l}\text { Development } \\
\text { temperature } \\
\text { and number of } \\
\text { seed parents }\end{array}$ & $\begin{array}{l}\text { Number of } \\
\text { capsules } \\
\text { tested }\end{array}$ & $\begin{array}{l}\text { Number of } \\
\text { capsules giving } \\
\text { one or more full } \\
\text { red progeny }\end{array}$ & $\begin{array}{l}\text { Number of } \\
\text { progeny } \\
\text { grown }\end{array}$ & $\begin{array}{l}\text { Number of } \\
\text { full red } \\
\text { progeny }\end{array}$ \\
\hline $\begin{array}{l}\text { palrec/ } \\
\text { palrec }\end{array}$ & $\begin{array}{l}15^{\circ} \text { C. (11) } \\
25^{\circ} \text { C. (13) }\end{array}$ & $\begin{array}{l}64 \\
63\end{array}$ & $\begin{aligned} 21 & (33 \%) \\
0 & (0 \%)\end{aligned}$ & $\begin{array}{l}4742 \\
5193\end{array}$ & $\begin{array}{c}110(2 \cdot 3 \%)^{*} \\
0(0 \%)^{*}\end{array}$ \\
\hline $\begin{array}{l}\text { niv rec/ } \\
\text { niv rec }\end{array}$ & $\begin{array}{l}15^{\circ} \text { C. (17) } \\
25^{\circ} \text { C. (19) }\end{array}$ & $\begin{array}{l}68 \\
47\end{array}$ & $\begin{array}{ll}40 & (59 \%) \\
22 & (47 \%)\end{array}$ & $\begin{array}{l}2294 \\
2108\end{array}$ & $\begin{array}{l}79(3.4 \%) \\
78(3.7 \%)\end{array}$ \\
\hline
\end{tabular}


Such changes seem characteristic of niv rec and are perhaps invariably associated with a "flush" of anthocyanin pigment that spreads over the entire corolla except for the face area where the "flush" pigment is aurone (fig. 2D). At first the flush may be patchy and similar to the effect of the unstable palmaculosa allele (Fincham and Harrison, 1967); as the inflorescence develops, later flowers become fully flushed. The flush phenomenon will be discussed later in the section on paramutation but its frequent association with a reduction in somatic mutation rate necessitates mention in this context. An inflorescence showing high mutability may change to a low rate without any conspicuous flush although one would usually develop later; while the plant is in the transition stage between high and low mutability many sectors of high mutability can occur alongside sectors of very low mutability (see fig. $2 \mathrm{E}$ ).

If nivrec is heterozygous with the stable reconstituted Tübingen niv both flushing and flaking can occur uniformly throughout the same corolla rather than in sectors which indicates that flushing is not in this instance a phenotypic effect of a stable dominant allele of niv. Flushing is not conspicuous in $\mathrm{F}_{1}$ s between niv ("Snowman") and nivrec.

The allele niv ${ }^{c a r}$, referred to above gives an intensity of pigment similar to "flush" and mutant sites of this lower pigment intensity are frequent in homozygous nivrec plant (see fig. 1). Streaks of carnea intensity and unaccompanied by full red flakes are frequently seen in nivrec/niv (Tübingen reconstituted) heterozygotes (fig. $2 \mathrm{~F}$ ); these streaks usually give way to overall flush in later developing flowers.

Consideration has to be given to the possibility that these streaks and the late-developing flush are both due to the accumulation of mutations to niv car as the plant ages. However, the very regular timing and overall expression of the flush contrasts with the randomly sited and timed mutations of nivrec to $\mathrm{Niv}^{+} ; n i v^{r e c}$ to $\mathrm{Niv}^{+}$is usually seen in discrete flakes and seldom as wholly pigmented flowers or spikes, while the flush tends to affect all later-developing flowers and is spread over the whole of the corolla. Another feature of flushing which tends to distinguish it from the manifestations of high mutability is that it appears to affect both alleles virtually simultaneously in a niv rec/nivrec homozygote. If one allele were to mutate to niv car, the other should still continue to mutate to $\mathrm{Niv}^{+}$, giving darkly pigmented spots against a highly pigmented background. The onset of flushing in a niv rec homozygote, however, is accompanied by a great (much more than 50 per cent.) reduction in frequency of dark red spots, though a few do still sometimes occur.

\section{(d) Changes in timing and pattern of somatic mutation}

The time during flower development at which a somatic mutation of either pal rec to $\mathrm{Pal}^{+}$or niv ${ }^{\text {rec }}$ to $\mathrm{Niv}^{+}$occurs dictates the size of the flake of pigment; early mutations during flower development result in large pigmented streaks or sectors and late mutations yield flakes of only a few cells each (Harrison and Carpenter, 1968). If the mutation occurs prior to flower development the whole inflorescence may be somatically (i.e. epidermally) $\mathrm{Pal}^{+}$or $\mathrm{Niv}^{+}$but germinally the flowers remain pal ${ }^{r e c}$ or nivere. Plants may show a wide range of flake sizes on the flower or else the timing may be restricted so that only large or small sites predominate. In fig. $2 \mathrm{~B}$ the flower (typical of all flowers on the plant) showed marked reduction of somatic mutations on the lower half of the flower (some small flakes were present 
but are not visible on the photograph). Somatic mutation has thus been mainly restricted to a particular part of the corolla; as both halves would be developing at approximately the same time this expression is probably not merely a function of timing. In fig. 3 , however, small mutant sites occur very densely and are restricted to the periphery of the corolla. These new patterns of spatial restriction of mutant sites, which originally arose in single plants of the niv rec stock, were each maintained more or less true to type in lines established by selfing of these plants.

Other changes in pattern of somatic mutability occurred in sectors of flowers or shoots rather than in whole plants. Fig. $2 \mathrm{C}$ illustrates a bilateral effect of a marked change in mutation frequency; the left-hand lobe as shown on the photograph had 1071 mutant sites while the right-hand lobe contained 6992 mutant sites. Some flowers on the inflorescence were totally low, others totally high in site number.

In contrast with this situation fig. 4 shows a flower in which the site numbers of the two distinct areas are not very dissimilar, but site size is different. Because of the impossibility of counting a complete traverse on the left hand lobe a $3 \mathrm{~mm} .{ }^{2}$ area of each lobe was counted. This area on the left-hand lobe had 510 mutant sites, containing 2738 pigmented cells (5.4 cells/site), while on the right-hand lobe there were 578 sites, with 801 pigmented cells $(1.4$ cells/site $)$. This striking difference in site size indicates that there was a change in the timing of mutation.

These changes in pattern may be due to new alleles at niv ${ }^{r e c}$ or, especially where the change is in mutation frequency as in fig. $2 \mathrm{C}$, to a change at a different "stabiliser" locus. The latter explanation has been suggested for parallel situations involving palrec (Harrison and Fincham, 1968).

\section{(e) Paramutation in crosses between nivea-recurrens and nivea}

Homozygous niv flowers are completely lacking in pigment and are very constant in this respect. The niv rec flowers are often similar, except in the areas in which mutations to $\mathrm{Niv}^{+}$have occurred. The pigment block in niv rec, however, appears less complete than in niv and an overall flush may spread over the corolla (anthocyanin on the lobes and tube; aurone on the face). The appearance of a flush varies between lines and is more likely to appear as the plant ages and, as we have seen, is usually accompanied by a decrease or sometimes a complete loss of flaking (fig. 5). This is not an artefact caused by failure to detect flakes of $\mathrm{Niv}^{+}$tissue since the dark flakes of anthocyanin pigment are clearly seen against the flush on the lobes and on the corolla tube and the aurone flakes on the face are also clearly distinguishable against any pale aurone flush.

When $\mathrm{F}_{1}$ heterozygotes, niv ${ }^{r e c} /$ niv, are examined, variations in the expression of flaking are dependent on: (a) the temperature at which the $\mathrm{F}_{1}$ seed was produced; (b) whether the cross was niv $\times \times n i v^{\text {rec }}{ }^{t}$ or the reciprocal; (c) the niv rec line used; (d) the niv line used.

The frequency of flaked plants in the $\mathrm{F}_{1}$ (nivrec $q \times$ niv $\left.\sigma^{*}\right)$ varied significantly at the two temperatures at which the $F_{1}$ seed matured: 34 per cent. at $15^{\circ} \mathrm{C}$. and 11 per cent. at $25^{\circ} \mathrm{C}$. (table 4 ). When the reciprocal cross was made flaking virtually disappeared, whether the $\mathrm{F}_{1}$ seed was matured at $15^{\circ}$ or $25^{\circ} \mathrm{C}$. In contrast with this near disappearance of instability in the $\mathrm{F}_{1}$ of niv $\times$ niv ${ }^{r e c}$ when niv ${ }^{r e c}$ exhibited its instability throughout the corolla, table 4 shows that a high frequency of flaked progeny was obtained when 
niv ${ }^{r e c}$ showed instability only on the periphery of the corolla (see fig. 3 ). The 83 and 95 per cent. flaking in the progenies occurred when niv was the female parent; if the crosses of normal flaking nivrec are taken as a guide then nivrec (Peripheral) $\times$ niv should have an even greater frequency of flaking. Unfortunately only six plants were obtained from this cross but all six were flaked.

TABLE 4

Number of flaked plants from $F_{1}$ s of nivec and niv grown at two temperatures

Temperature of $F_{1}$ seed maturation

\begin{tabular}{|c|c|c|c|c|c|c|}
\hline \multirow[b]{2}{*}{$F_{1}$ parents } & \multicolumn{3}{|c|}{$15^{\circ} \mathrm{C}$. } & \multicolumn{3}{|c|}{$25^{\circ} \mathrm{C}$. } \\
\hline & Flake + & Non-flake & $\begin{array}{c}\% \text { Flake and } \\
\text { number of } \\
\text { crosses } \dagger\end{array}$ & Flake + & Non-flake & $\begin{array}{c}\% \text { Flake and } \\
\text { number of } \\
\text { crosses } \dagger\end{array}$ \\
\hline niv reco $\times$ niv*o & 200 & 382 & $34 \% \quad(13)$ & 63 & 509 & $11 \%(12)$ \\
\hline $\begin{array}{l}\text { niv*o } \times \text { niv rec }{ }^{*} \\
\text { niv } * 0 \times \text { niv } \\
\text { rec }\end{array}$ & 1 & 226 & $0.4 \% \quad(3)$ & 0 & 220 & $0 \% \quad(4)$ \\
\hline $\begin{array}{c}\text { (Peripheral) }{ }^{\star} \\
\text { niv }\end{array}$ & 204 & 41 & $83 \%$ & 127 & 7 & $95 \% \quad(2)$ \\
\hline$\times n i v * \sigma$ & 6 & 0 & $100 \%$ & - & 一 & - \\
\hline $\begin{array}{l}\text { * The same par } \\
\dagger \text { Bracketed fig } \\
\text { † All flaked pro } \\
\text { arents. }\end{array}$ & $\begin{array}{l}\text { amutage } \\
\text { ares give } \\
\text { geny we }\end{array}$ & $\begin{array}{l}\text { nic niv stocl } \\
\text { the number } \\
\text { re of norm }\end{array}$ & $\begin{array}{l}\text { was used in a } \\
\text { f different fe } \\
\text { pattern incl }\end{array}$ & $\begin{array}{l}\text { crosses. } \\
\text { ale plant } \\
\text { ding thos }\end{array}$ & $\begin{array}{l}\text { ts used in th } \\
\text { e from peri }\end{array}$ & $\begin{array}{l}\text { e crosses. } \\
\text { pherally flaked }\end{array}$ \\
\hline
\end{tabular}

The $\mathrm{F}_{1}$ plants of niv $\times$ niv ${ }^{r e c}$ were selfed and the $\mathrm{F}_{2}$ plants scored for any reappearance of flaking. The $F_{1}$ plants which showed flaking gave some flaked progeny while all the plants in which flaking had disappeared gave $\mathrm{F}_{2} \mathrm{~s}$ in which flaking was still absent. Thus, provided the cross was conducive to the disappearance of the instability of niv rec, then the new form persisted at least into the $F_{2}$ generation.

It is proposed to refer to this apparently stable change in niv rec, following a cross to a niv stock (especially when the latter was the seed parent), as paramutation. The changes in nivec expression, and in the timing of its mutation, during plant development may also be considered as manifestations of paramutation in the sense of Brink, Styles and Axtel (1968).

Two niv lines have been used in crosses with various niv rec types: one (that used in the crosses in table 4) is paramutagenic and the other is not. As we have seen, in crosses of the paramutagenic line considerable paramutation occurred, particularly in crosses with the niv ${ }^{r e c}$ lines showing a normal flaking distribution. Additional data confirmed that when nivec was the female parent greater paramutation occurred when the crosses and seed maturation were completed at $25^{\circ} \mathrm{C}$. as opposed to $15^{\circ} \mathrm{C}$. In one of these crosses no flaked plants occurred in the $\mathrm{F}_{1}$ or $\mathrm{F}_{2}$; in two other crosses, only 3.6 and 6 per cent. showed flaking in the $F_{1}$ and when $F_{1}$ flaked plants were selfed all the resultant $\mathrm{F}_{2}$ plants were non-flaked. However, when a comparable cross was done at $15^{\circ} \mathrm{C}$. and $\mathrm{F}_{1}$ seed matured at this temperature, 42 per cent. of the $\mathrm{F}_{1}$ were flaked and the $F_{2}$ raised from the flaked $F_{1}$ plants gave 17.3 per cent. flaked. (No additional data were available for the reciprocal crosses.) A striking dissimilarity was found when the same paramutagenic niv was used as female with a peripheral flaking nivec (a line, shown in fig. 3, established 


\section{Plate I}

FIG. 1.-Photomicrograph of a corolla lobe of nivrec/nivrec with a sector of somatic mutation of niv rec to a niv rubra type pigment intensity (A) together with an adjacent sector of nivcarnea intensity (B); both sectors have attendant flakes of somatic $\mathrm{Niv}^{+}$mutations which arise from the remaining unstable nivec allele. The broad central sector (C) in which flaking is reduced may be the result of either a somatic mutation of the stabiliser or one of the nivrec alleles mutating to a stable acyanic allele.

FiG. 2.-Various expressions of flaking and flushing in nivrec flowers. (A) Normal flaking in nivrec/nivrec. (B) Flaking in nivrec/nivrec mostly restricted to upper lobes. (C) Unequal flaking on two halves of corolla of nivec/nivrec plant. As there was no flushing present the reduction was possibly a somatic mutation of the putative niv ${ }^{r e c}$ stabiliser and not due to paramutation. (D) Reduced flaking with attendant carnea type flush in nivrec/nivrec. (E) Sectors of high flaking in a nivrec/nivrec flower with a low flaking background together with a pale overall flush. There are yellow sites on the face area but with no conspicuous aurone flush. (F) Sectors of pale nivearnea intensity on a niv ${ }^{r e c} \times$ niv $\mathbf{F}_{1}$ plant. No full red flaking present anywhere on corolla; streaks of aurone also occurred on the face area.

\section{Plate II}

Fig. 3.-Peripheral flaking (very dense small sites) on nivrec/nivec $\left(\mathbf{M}^{\text {r }} 169^{\mathbf{R}_{\overline{3}}}\right)$ grown at $15^{\circ} \mathrm{C}$.

FIG. 4.-A nivrec/nivec corolla in which the more heavily pigmented part has an earlier pattern of mutational events; the sites are larger but the number of sites is essentially similar to that on the less pigmented parts of the corolla's lobes (510 mutant sites with 2738 pigmented cells compared with 578 mutant sites with 801 pigmented cells on $3 \mathrm{~mm}^{2}$. areas).

\section{Plate III}

Fig. 5.-An inflorescence of nivrec/nivrec $\left(\mathrm{Gl}^{\mathrm{r}} \mathrm{2}^{2}\right)$ showing the onset of somatic paramutation. Lower flowers are flaking normally; middle flowers have a faded flush with a reduced number of flakes; the newly opened top flowers have a dark flush (with no attendant flakes) that fades as the flowers age. 


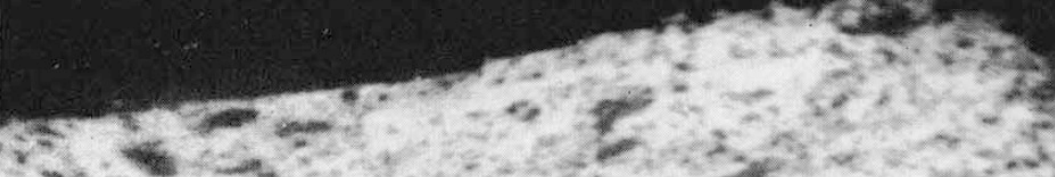

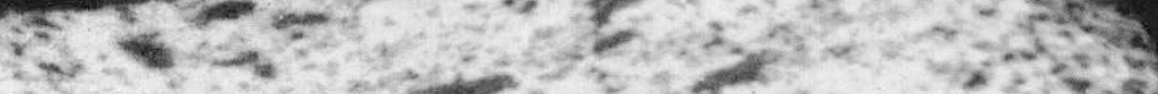

2.

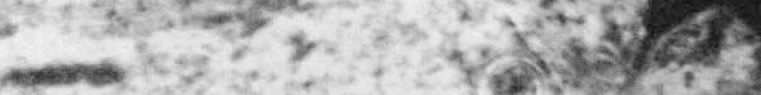

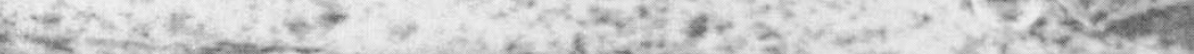

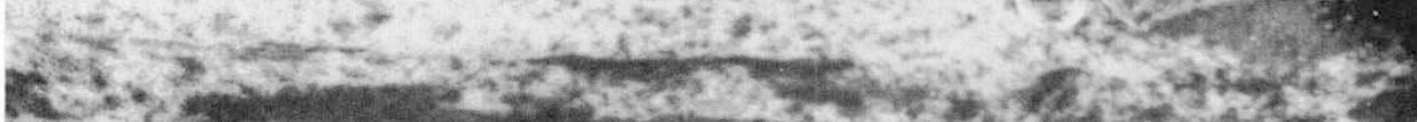

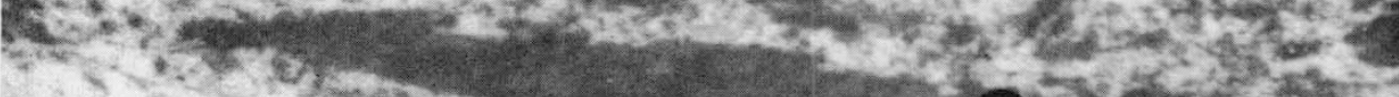

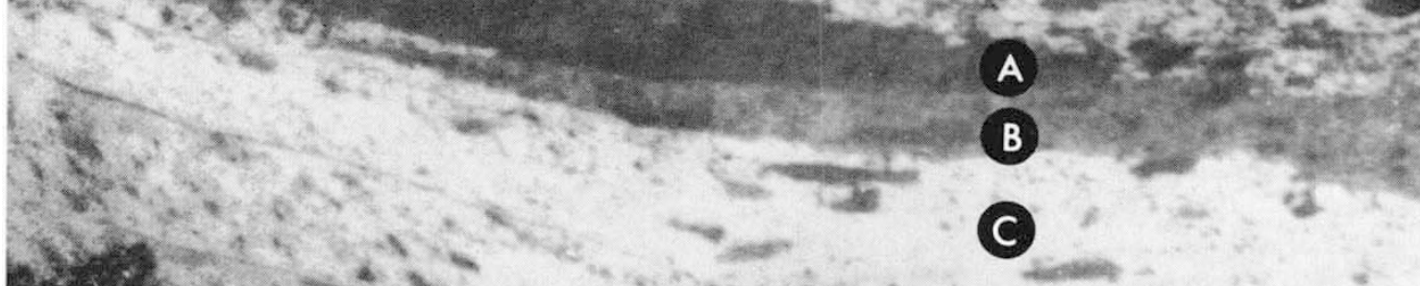

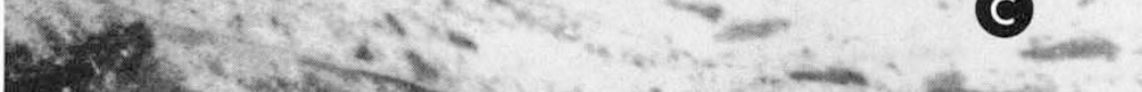

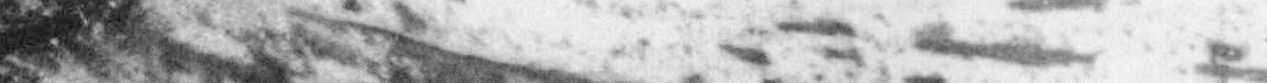
6. 3 -

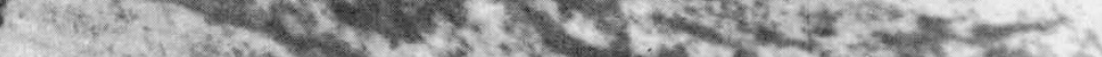

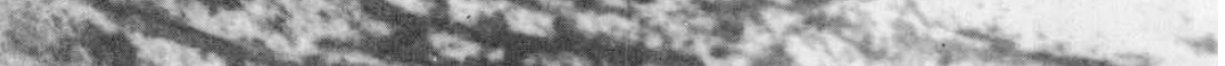

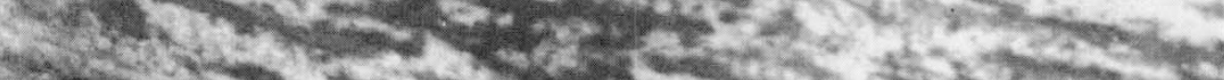

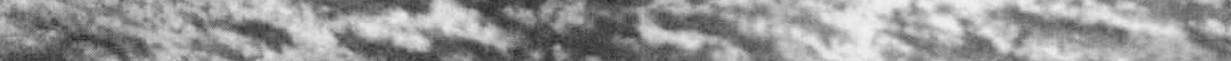

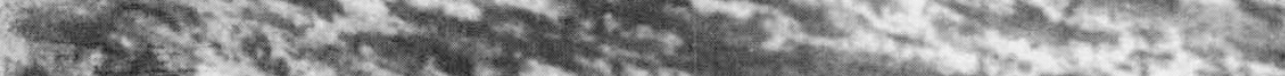

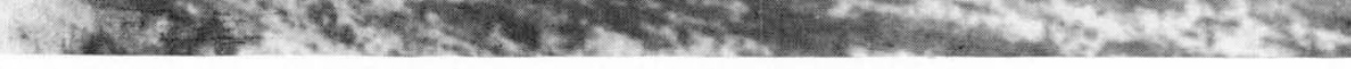
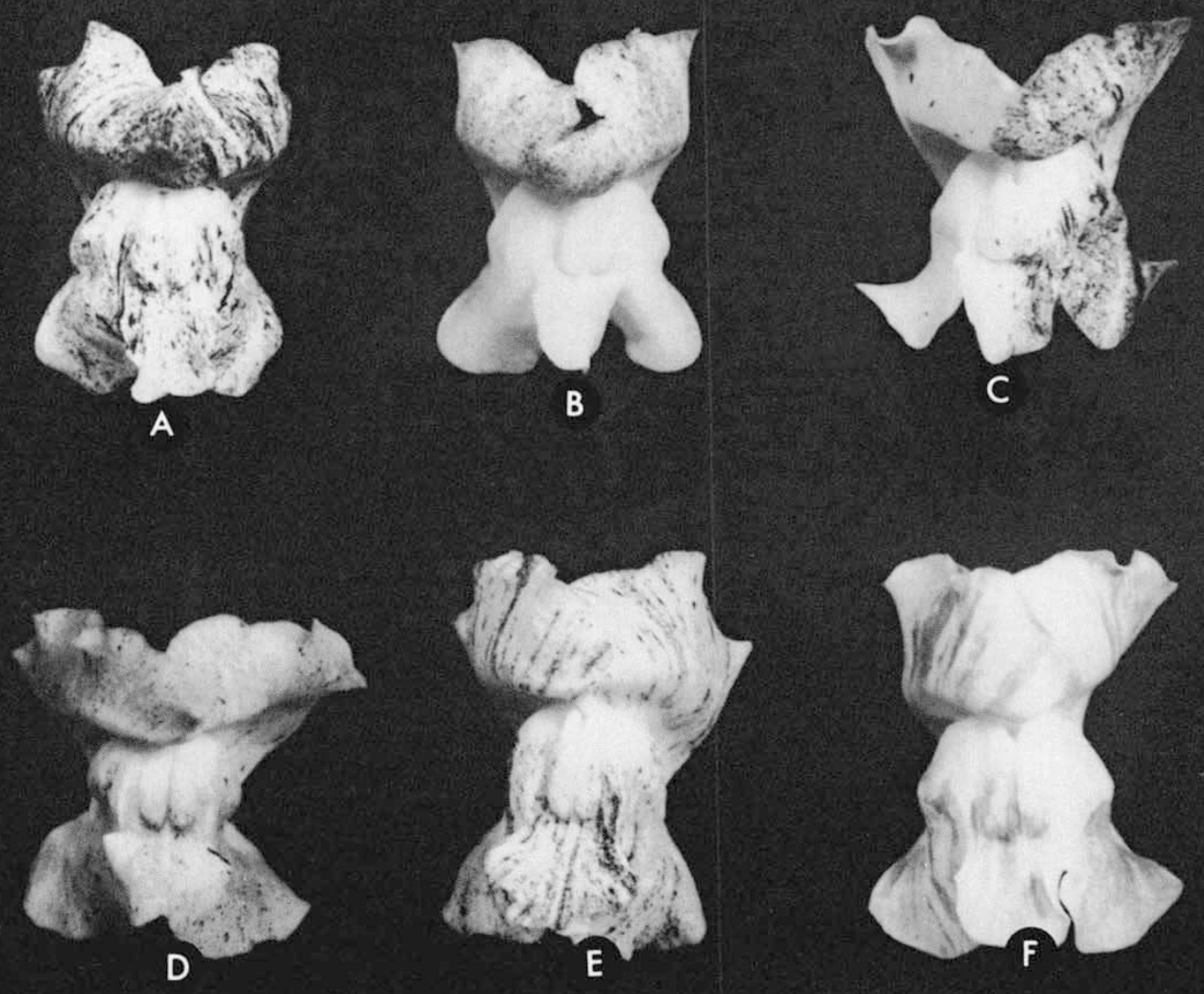

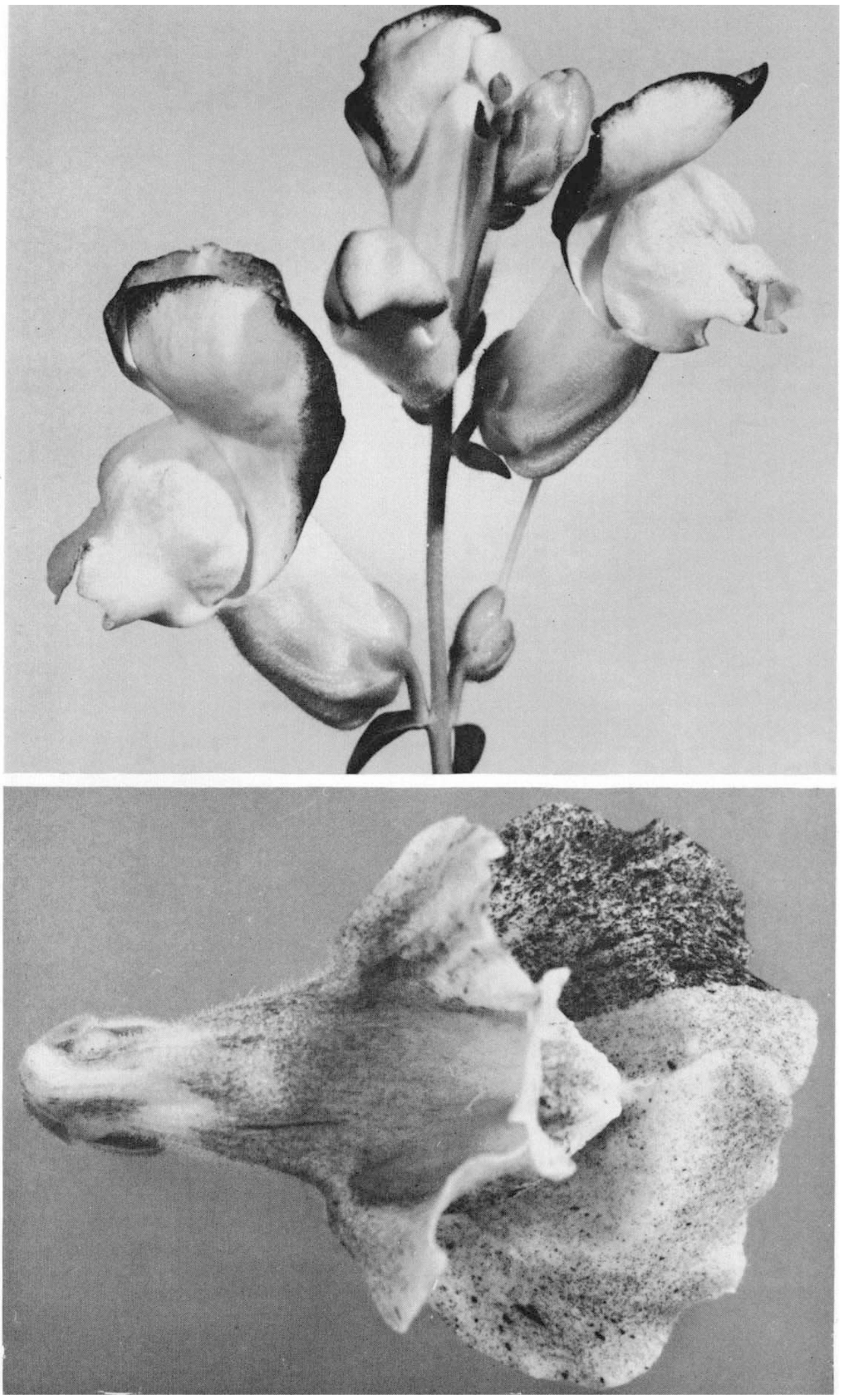

from an aberrant plant in the original niv rec stock) and the cross and seed maturation completed at $15^{\circ} \mathrm{C}$.; in this case 87 per cent. of the $\mathrm{F}_{1}$ was flaked and various amounts of flaking occurred in the $\mathrm{F}_{2}$ (from 5 to 40 per cent.) according to the particular $\mathrm{F}_{1}$ plant used.

The non-paramutagenic niv (Suttons "Snowman") was used as female parent with peripheral flaking niv rec and all the $\mathrm{F}_{1}$ plants were highly flaked in a normal rather than a peripheral pattern. A similar cross but with a nivrec of normal flaking distribution gave an $F_{1}$ all of which were normally flaked but at a lower frequency.

From these results it would appear that varying sensitivity to paramutation can exist. Also as two niv lines differing in paramutagenicity have already been established it is probable that a range of paramutagenic lines from highly active to inactive could be established from nivea stocks of dissimilar origin.

In contrast to these results with niv rec, no indication of paramutation has been seen in the pallida material. The nearest cross for comparison with the nivec crosses would be pal rec by the nearly acyanic paltncta. Reciprocal crosses of these two allelic stocks gave $F_{1}$ plants all of which were flaked, though at rather a low frequency (due to the presence of one or more semidominant stabiliser genes in the pal ${ }^{t i n}$ stock). Selfing of these $F_{1}$ plants led to segregation of highly flaked plants in the $F_{2}$. Similar retention of the full inherent mutability of pal ${ }^{r e c}$ has been found when palrec is associated with any other allele of the series. In all crosses of palrec with all other alleles in the series a full expression of instability was obtained.

\section{(f) Stabiliser systems}

An unlinked semi-dominant controller of mutability of palrec has been identified and called palrec Stabiliser (St) (Harrison and Fincham, 1968). Comparative counts of mutant sites on one corolla lobe are in the following ranges: St/St 0-20; St/st 100-1000; st/st 3000-10,000. There is some evidence that $S t$ can be highly unstable and in such cases multiple streaks and patches of varying frequencies of flaking occur. Stocks of $s t / s t$ and $S t / S t$ have been established and clear segregations have been recorded when crosses to palrec and backcrossed to the Stabiliser stocks.

Crosses of niv rec (inbred for four generations since reconstitution with eluta) to the $S t$ and $s t$ stocks were made and large $\mathrm{F}_{2}$ progenies scored for flaking intensity. The homozygous niv rec plants in the $F_{2}$ from the cross to $s t / s t$ were compared with the $\mathrm{F}_{2}$ in which $S t / s t$ would be segregating. No difference in flaking frequency between the two sets of niv rec was observable. There was considerable variation in the frequency of flaking but it was similar in both $\mathrm{F}_{2} \mathrm{~s}$. Thus we can conclude that the palrec stabiliser system does not affect nivec; this conclusion would be invalid only if the $S t / s t$ locus were fairly closely linked to the nivea locus. The degree of inbreeding of the nivrec parents was low but any heterozygosity would be common to both $\mathrm{F}_{2}$ s.

A somatic instability in the control of the mutable nivrec similar to the one for pal ${ }^{r e c}$ nevertheless seems to occur, and fig. $2 \mathrm{E}$ illustrates this effect. Crosses of high and low mutability lines $(\mathrm{H} \mu$ and $\mathrm{L} \mu)$ of pal ${ }^{r e c}$ were made in various ways with high and low mutability lines of nivec. The results are recorded in table 5. The high lines of palrec have already been established as being homozygous for recessive stabiliser and the low lines homozygous for dominant Stabiliser (Harrison and Fincham, 1968) it is proposed to 
designate these as $p$-st $/ p$-st and $p$-St $/ p$-St respectively. A similar situation is proposed for niv rec and these stabilisers will be called $n$-st $/ n$-st and $n-S t / n-S t$ to distinguish the probable duality of control.

TABLE 5

Flaking of parental types in $F_{2}$

\begin{tabular}{|c|c|c|c|c|c|c|c|}
\hline & Genotype of cross & & L & $\mathbf{M}$ & $\mathbf{M} / \mathbf{H}$ & $\mathrm{H}$ & $\begin{array}{l}\text { Inferred stabiliser } \\
\text { content of parents }\end{array}$ \\
\hline (A) & $\underset{\times}{\operatorname{palrec}} \underset{\times}{\left(\mathrm{H}_{\mu}\right) \mathrm{M} 224^{14}}$ & palrec & & 1 & 8 & 9 & $p-s t / p-s t+n-s t / n-s t$ \\
\hline (B) & $\begin{array}{l}\text { niv }{ }^{\text {rec }}\left(\mathbf{H}_{\mu}\right) \mathbf{M} 161^{\mathrm{R} 1} \\
\text { palrec }\left(\mathbf{H}_{\mu}\right) \mathbf{M} 224^{6}\end{array}$ & $\begin{array}{l}\text { nivrec } \\
\text { palrec }\end{array}$ & & & & $\begin{array}{l}13 \\
21\end{array}$ & $\begin{array}{l}p-S t / p-S t+n-s t / n-s t \\
p-s t / p-s t+n-s t / n-s t\end{array}$ \\
\hline (C) & $\begin{array}{l}\times \\
\text { niv } \\
\text { palrec }(\mathrm{H} \mu) \mathrm{M} 223^{73} \\
(\mathbf{L} \mu) \mathbf{M} 3^{7}\end{array}$ & $\begin{array}{l}\text { nivec } \\
\text { palrec }\end{array}$ & 13 & 1 & 1 & $\begin{array}{r}24 \\
4\end{array}$ & $\begin{array}{l}p-s t / p-s t+n-s t / n-s t \\
p-S t / p-S t+(n-S t / n-S t)\end{array}$ \\
\hline (D) & 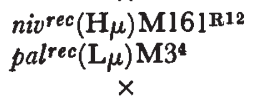 & $\begin{array}{l}\text { nivere } \\
\text { palrec }\end{array}$ & $\begin{array}{r}10 \\
3\end{array}$ & $\begin{array}{l}3 \\
2\end{array}$ & $\begin{array}{l}1 \\
1\end{array}$ & 7 & $\begin{array}{l}p-s t / p-s t+n-s t / n-s t \\
p-S t / p-S t+n-s t / n-s t\end{array}$ \\
\hline (E) & $\begin{array}{l}\text { nivecc }\left(\mathrm{H}_{\mu}\right) \mathrm{M} 223^{73} \\
\operatorname{palrec}(\mathrm{L} \mu) \mathrm{M} 3^{10} \\
\times\end{array}$ & $\begin{array}{l}\text { niv rec } \\
\text { palrec }\end{array}$ & 10 & & 1 & $\begin{array}{l}7 \\
4\end{array}$ & $\begin{array}{l}(p-S t / p-S t) \dagger+n-s t / n-s t \\
p-S t / p-S t+n-s t / n-s t\end{array}$ \\
\hline (F) & $\begin{array}{c}\operatorname{niv}^{r e c}(\mathrm{~L} \mu) \mathrm{M} 195^{\mathrm{R} 2} \\
\operatorname{niv} r e c(\mathrm{H} \mu) \mathrm{M} 161^{\mathrm{RI}} \\
\times\end{array}$ & $\begin{array}{l}\text { niv rec } \\
\text { niv rec }\end{array}$ & 20 & 4 & 4 & $\begin{array}{r}4 \\
23\end{array}$ & $\begin{array}{l}p-s t / p-s t+n-S t / n-S t \\
p-S t / p-S t+n-s t / n-s t\end{array}$ \\
\hline (G) & $\begin{array}{l}\text { palrec }\left(\mathrm{H}_{\mu}\right) \mathrm{M} 224^{9} \\
\text { niv rec }_{(\mathrm{H}}(\mathrm{H}) \mathrm{M} 161^{\mathrm{R} 12} \\
\times\end{array}$ & $\begin{array}{l}\text { palrec } \\
\text { nivrec }\end{array}$ & $\begin{array}{l}2 \\
2 \ddagger\end{array}$ & 4 & $\begin{array}{l}9 \\
4\end{array}$ & $\begin{array}{r}7 \\
16\end{array}$ & $\begin{array}{l}p-s t / p-s t+n-s t / n-s t \\
(p-s t / p-s t)+n-s t / n-s t\end{array}$ \\
\hline (H) & $\begin{array}{l}\text { palrec }(\mathrm{L} \mu) \mathrm{M} 3 \\
\text { niv }^{\text {rec }}(\mathrm{L} \mu) \mathrm{M} 195^{\mathrm{R} 2}\end{array}$ & $\begin{array}{l}\text { palrec } \\
\text { nivrec }\end{array}$ & $\begin{array}{l}24 \\
15\end{array}$ & $\begin{array}{l}5 \\
6\end{array}$ & $\begin{array}{l}1 \\
3\end{array}$ & 10 & $\begin{array}{l}p-S t / p-S t+n-s t / n-s t \\
p-s t / p-s t+n-S t / n-S t\end{array}$ \\
\hline & palrec $(\mathrm{L} \mu) \mathrm{M} 3^{10}$ & palrec & 15 & 10 & 2 & 8 & $p-S t / p-S t+n-s t / n-s t$ \\
\hline
\end{tabular}

* $n-S t / n-S t$ recorded as there are many $L \mu$ nivrec types in $F_{2}$ but these may be due to an early somatic paramutation effect which by affecting nivrec would reduce the frequency of flaking. It is perhaps plausible to assume $n-s t / n \rightarrow s t$ as other M3 parents are found to accord with a $n-s t / n-s t$ description.

$\dagger$ Some palrec types in $\mathbf{F}_{2}$ are slightly high in flaking intensity for a $p-S t / p-S t$ description but this is closer than $p-s t / p-s t$ for the nivrec contribution.

$\ddagger$ The $\mathrm{L}_{\mu}$ nivrec types may here be due to somatic paramutation affecting nivrec and thereby reducing the frequency of flakes.

Note: $\mathbf{F}_{2}$ plants doubly homozygous for palrec and niv rec are omitted from the table.

The flaking segregants in the $\mathrm{F}_{2} \mathrm{~s}$ of the eight crosses were classified into Low (c. 30 sites/lobe), Medium (500), Medium/High (1000) and High $(3000+)(\mathrm{L}, \mathrm{M}, \mathrm{M} / \mathrm{H}, \mathrm{H})$ flaking intensity and related to the homozygous niv ${ }^{r e c}$ and palrec parental types. The numbers cited are a rough guide only; it is not possible to define flaking categories in precise terms, since the mutation frequency of both palrec and niv ${ }^{r e c}$ depend critically on temperature. The very low flaking plants homozygous for both niv ${ }^{r e c}$ and pal ${ }^{r e c}$ were identified by an exposure to ammonia vapour (see section vii) and omitted from these assessments. The intensity of flaking of the parents determined the stabiliser constitution appertaining to the unstable allele carried. Thus, for the first cross in table 5 the stabiliser control for palrec $(\mathrm{H} \mu)$ is designated with some confidence $p$-st/p-st; however, it is only by inference that the stabiliser control for niv ${ }^{r e c}$ carried by the pal ${ }^{r e c}$ parent is designated $n$-st $/ n$-st. 
The inference in this case is based on the 13 niv rec segregants in the $\mathrm{F}_{2}$ all of which are of high flaking intensity. Similarly, as nine pal ${ }^{r e c} \mathrm{~F}_{2}$ segregants are high while nine are not we can deduce that $p-S t / p-S t$ is likely to be present in the niv ${ }^{r e c}$ parent. If all eight $\mathrm{F}_{2} \mathrm{~s}$ are analysed in this way then in about half of the inferred stabiliser contents of the parents there is a difference between the putative niv ${ }^{r e c}$ system and that for palrec.

Although the present data do not prove conclusively the control of the two unstable alleles by independent stabiliser systems it is noteworthy that all deductions for the joint stabiliser content of the inbred L $\mu$ palrec line (M3) were $p-S t / p-S t, n$-st/n-st (except for one doubtful case in which paramutation possibly obscured the true recording of the flaking intensities). Cross (F) shows clearly that the nivrec content of both parents must be $n$-st $/ n$-st and that as there are a number of low flaking plants of palrec in the $\mathrm{F}_{2}$ the nivrec parent must have contributed $p-S t$. To attribute the variation in mutability among the $\mathrm{F}_{2}$ niv ${ }^{r e c}$ plants to segregation of two alleles, $n$-st and $n-S t$, is doubtless an oversimplification since segregations are not clear cut nor in clear mendelian ratios. The data are, however, not inconsistent with the hypothesis of one pair of alleles of major effect segregating together with a number of less potent modifiers.

In the absence of further evidence on the dominance relationship of the two systems it is proposed that two similar but independent and unlinked systems exist (that may well be more complex than the single gene system propounded) and that each provides a substantial, but not absolute, control over one of the two mutable genes. The segregations listed in table 5 also indicate the presence of modifiers for the stabiliser system.

\section{(g) Association of nivea-recurrens and pallida-recurrens in the same genotype}

If the two unstable recurrens alleles of nivea and pallida are incorporated homozygously into the same genotype neither can express the mutated sites of full red anthocyanin unless the other has also mutated in the same tissue (Harrison, 1971). As the face area sites of aurone are solely controlled by nivec, mutation of palrec in the same genotype is not required for this expression. It was not found that the mutation rate of either unstable allele was strongly affected by the presence of the other; coincident mutation of the two unstable alleles in the same tissue occurred at a rate approximating randomness within a factor of two.

Somatic mutations of $n i v^{r e c}$ on the corolla (excluding the face area), that are unaccompanied by a coincident mutation of palrec, can be identified by exposing the flower to ammonia fumes which shows the flavone producing areas as yellow. Large flavone producing areas represent early mutations of niv ${ }^{r e c}$ and subsequent mutations of palrec can be seen as anthocyanin sites on a flavone producing area. The previous account (Harrison, 1971) noted tha most or possibly all anthocyanin-containing flakes occurred within sectors of flavone-producing cells, suggesting that palrec only mutated after nivrec had already done so. If palrec mutated first then a cluster of anthocyanin sites would be seen against a white aflavonic background. This was rarely seen in the earlier experiments. However, recent work using the sulfurea gene instead of ammonia to identify the presence of flavone has suggested that the order of mutation is not obligatory, in that small groups of cyanic cells did occur within apparently white areas. The question whether palrec can mutate while niv is absolutely inactive is not yet settled, however, since a change of 
niv rec to "flush" expression might be hard to detect on the basis of aurone pigment alone. The plants examined so far do. seem to show an absence of palrec mutations occurring early prior to the mutation of nivec. Such early mutations of palrec, if they occurred in palrec pal ${ }^{r e c}$ niv ${ }^{r e c}$ niv ${ }^{r e c}$ with the frequency observed in palrec palrec $\mathrm{Niv}^{+}$plants, should give large sectors or sometimes whole flowers or shoots in which the usual numerous yellow spots were entirely replaced by a similar frequency of full red against a white background. A continued failure to find such large sectors would suggest that at least early mutations of palrec are dependent for their occurrence on $\mathrm{Niv}^{+}$activity. This in turn might suggest a link between palrec mutation and transcription, the latter being induced by the presence of the metabolic substrate for $\mathrm{Pal}^{+}$activity.

\section{(h) The inability of chemical mutagens and $X$-irradiation to alter the instability of the recurrens alleles}

$\mathrm{X}$-irradiation given at different doses for varying lengths of time to pollen, ovules and corolla tissue failed to increase the frequency of germinal or somatic mutations. Ethyl methanesulphonate (EMS) also had no effect. Seeds of palrec were soaked and agitated in a range of concentrations of EMS (0.025-0.8 per cent.) for 18 hours. The seeds were washed and immediately sown and the resultant plants scored for the frequency of $\mathrm{Pal}^{+}$plants. No effect upon the instability of the recurrens allele was observed.

The strongly mutagenic alkylating agent diethyl sulphate (DES) was tested on the pollen of palrec and niv ${ }^{r e c}$ at a concentration of 0.05 per cent. in liquid paraffin. The treated palrec pollen produced 4.8 per cent. $\mathrm{Pal}^{+}$ (based on 269 plants) compared with a control of 4.2 per cent. (based on 616 plants). The treated nivrec pollen produced 5.7 per cent. $\mathrm{Niv}^{+}$(based on 631 plants) and the control had 3.6 per cent. (based on 278 plants). The frequency of mutation of the unstable alleles palrec and niv rec was therefore not significantly altered by this type of treatment with DES $(P=0.2$ on the niv rec data).

\section{Discussion}

\section{(a) Comparison of pallida-recurrens and nivea-recurrens}

The two unlinked unstable alleles palrec and niv ${ }^{r e c}$ have many features in common, but several major differences are revealed. A summarised comparison of the two genes is shown in table 6 .

The main points of similarity are as follows: (a) the rec alleles prevent the production of anthocyanin but are highly mutable. (b) The genic instability expresses itself as flakes of pigment (most readily seen on the corollas) that are mainly mutations to the fully pigmented dominant wildtype. (c) An allelic series at each locus controls a range of pigment production varying from full pigmentation through several lesser intensities to acyanic. (d) Gametic mutations of both rec alleles to their wild-types ( $\mathrm{Pal}^{+}$ and $\mathrm{Niv}^{+}$) frequently occur. (e) The frequency of somatic mutations is inversely correlated with temperature, at least within the range $15^{\circ}$ to $25^{\circ} \mathrm{C}$. (f) Somatic and germinal mutations of the rec alleles to other members of the allelic series are often observed in addition to the very frequent mutations to wild-type. ( $g$ ) Independent genetic stabilisers control the frequency of somatic (and at least in the case of palrec gametic) mutations. (h) X- 
irradiation and chemical mutagens (EMS and DES) have little or no effect upon the instability of the rec alleles.

The two rec alleles differ in the following ways: (a) Differences in temperature have less effect upon the production of somatic mutations in niv rec than in pal rec. (b) Gametic mutations of pal ${ }^{r e c}$ to $\mathrm{Pal}^{+}$are significantly increased if pollination and seed maturation are effected at $15^{\circ} \mathrm{C}$. rather than at $25^{\circ} \mathrm{C}$.;

TABLE 6

Seed maturation temperature on flaking frequency in $\mathrm{F}_{1}$ with bottom recessive

Differences between reciprocal crosses in flaking frequency when recurrens allele is heterozygous with bottom recessive

Mutagenic effect on germinal and somatic mutation rate to $\mathrm{Pal}^{+}$and $\mathrm{Niv}^{+}$of DES, EMS and X-rays.

Effect of age of plant on flaking frequency and pattern

Timing difference in the onset of instability

Temperature effect upon somatic expression of instability

Effect of temperature on germinal mutation frequency

Stabiliser control of instability

Paramutability (no evidence for $\mathbf{P}$ )

\begin{tabular}{|c|c|c|}
\hline \multicolumn{3}{|c|}{ Effect } \\
\hline Not obvious & Moderate & Considerable \\
\hline $\mathbf{p}$ & - & $\mathrm{N}^{*}$ \\
\hline $\mathbf{P}$ & - & $\mathrm{N}^{*}$ \\
\hline $\mathbf{P}$ and $\mathbf{N}$ & - & - \\
\hline- & $\mathbf{P}$ & $\mathrm{N}^{*}$ \\
\hline - & $\mathbf{P}$ & $\mathrm{N}$ \\
\hline - & $\mathrm{N}$ & $\mathbf{P}$ \\
\hline $\mathrm{N}$ & - & $\mathbf{P}$ \\
\hline- & - & $\mathrm{P}$ and $\mathrm{N}$ \\
\hline - & - & \\
\hline
\end{tabular}

* An expression of paramutability. $\mathrm{P}=$ pallida-recurrens. $\mathrm{N}=$ nivea-recurrens.

for nivrec no difference between the two developmental temperatures was recorded. (c) The time at which somatic mutations occur is more variable in niv $^{\text {rec }}$ : earlier mutations are more frequently encountered for palrec. Lines of niver have been established from the original stock in which the mutant sites comprise only a few cells each; the expression of this finely stippled type of instability can also be restricted to the upper part of the corolla, the lower part carrying only a few isolated but small-sized sites. An even more unusual expression is the peripheral flaking (fig. 3) where numerous small-sized flakes are restricted to the margins of the corolla. No lines for early mutation (i.e. mainly large sectors) have been established for nivrec plants. (d) The reciprocal differences in flaking intensity and the effect of temperature upon crosses of niv and niv ${ }^{r e c}$, together with the changes in flaking frequency during the life of the niv rec plant, can all be regarded as manifestations of paramutation, in the sense of Brink, Styles and Axtel (1968). In contrast, the instability encountered in the palrec material, though sometimes extremely high, has much more of the randomness in time and place which one expects of " ordinary" mutation.

\section{(b) Paramutation}

Brink, Styles and Axtell (1968) have stated that paramutation is an intrinsic property of certain alleles and that paramutagenic factors only intensify the basic property. Paramutagenic factors do not, according to them, instigate the directed heritable change; they act as " adjuvants to the 
process, which can occur independently . ..." A comparison can be made between the published features of the maize system and the flush phenomenon and behaviour of niv $\times$ niv rec crosses. Although heterozygosity with a paramutagenic niv stock initiates considerable and sometimes complete paramutation, it can also occur somatically in homozygous lines. As a paramutable niv ${ }^{\text {rec }}$ plant develops and ages it invariably produces flowers of lowered flaking intensity or completely devoid of flakes which have developed an overall flush of pigment (anthocyanin on the lobes and aurone on the face area). The lateral branches on the plant may differ considerably in this respect and it is a common occurrence for normal flaking laterals to be on the same plant with other laterals carrying solely flushed flowers; later, however, as the laterals are superseded by new growth the whole plant will have flushed flowers. This behaviour is different from the random and relatively infrequent occurrence in palrec plants of sectors of palcarnea. The main inflorescence frequently can at first exhibit unflushed flaked flowers which later give way to solely flushed ones (fig. 5). This evidence indicates, in confirmation of the conclusions of Brink, Styles and Axtell, that paramutation can be progressive during plant development and that mosaicism for paramutation varies in different cell lineages. Paramutable nivrec expresses paramutation more readily in somatic cells than in the relatively undifferentiated meristematic germ tissue. If this did not occur it would be impossible to maintain a flaking line of the paramutable niv ${ }^{r e c}$ as the paramutant flush condition would soon predominate and replace the flaking propensity.

It has been shown by Styles and Brink (1969) that paramutation can occur in hemizygotes and they conclude that no transfer of material from the paramutagenic allele to its paramutable partner is necessary for the initiation of paramutation. A possible extension of this is that paramutation should be possible in homozygotes. Such paramutation could be the basis for the spectrum of different paramutable $R$ alleles in maize of differing geographic origins (Styles, 1967). In Antirrhinum somatic paramutation of niv rec is frequent and is possibly more easily identified than in the maize material; germinal paramutation, however, does not readily occur in homozygous nivrec plants. Although the stippling allele is the paramutagenic gene in maize and the flaking gene the paramutable one in Antirrhinum there are enough points in common to consider the paramutation phenomenon to be comparable in the two organisms.

\section{(c) Controlling systems}

The stabiliser system for palrec has considerable but not complete control over its mutability and can be fairly accurately determined (Harrison and Fincham, 1968). Perhaps because of the variations due to somatic paramutation a similar stabiliser system for nivec is not so easy to define. However, from the results available a genetic control of niv rec mutability independent of that for palrec does appear to operate.

McClintock (1951, 1953, 1956) has considered genetic instabilities to be caused by transposable extragenic units. When a unit is incorporated at the locus of a gene, it may affect genic action and be detected as mutation. It is, McClintock states, the insertion of an element adjacent to a gene that initiates instability. It is not yet clear whether transposable elements at the pal and niv loci are responsible for their instability. The fact that new un- 
stable alleles at two other loci-delila and Eluta-have been recovered from our stocks carrying palrec is suggestive of transposability, but proof that the new instabilities had such an origin is lacking. In addition to pal rec and niv ${ }^{r e c}$ other unstable (recurrens) alleles have been reported in Antirrhinum majus for incolorata, perlutea, graminifolia, mutabilis, and cycloidea-radialis (see summary in Stübbe, 1966). The role of unstable alleles is uncertain but it can hardly be insignificant when the number of unstable genes within an organism such as Antirrhinum is considered. Certainly considerable variation is possible (see Discussion in Harrison, 1971), and with the controlling systems outlined in the present paper there are several ways of accentuating or minimising the expression of instability.

Acknowledgments. - It is a pleasure to record our appreciation to Prof. J. R. S. Fincham and Prof. D. A. Hopwood for their help and interest during the preparation of this paper and to $\mathrm{Mr} \mathrm{L}$. S. Clarke for the production of the photographs.

\section{References}

BRINK, R. A. 1958. Paramutation at the $R$ locus in maize. Cold Spring Harb. Symp. Quant. Biol., 23, 379.

BRINK, R. A., STYLES, E. D., AND AXTELL, J. D. 1968. Paramutation; directed genetic change. Science, $159,161$.

FINCHAM, J. R. S., AND hARRIson, B. J. 1967. Instability at the pal locus in Antirrhinum majus. 2. Multiple alleles produced by mutation of one original unstable allele. Heredity, 22, 211.

HARRISON, B. J. 1971. Association of three highly mutable genes involving pigmentation in Antirrhinum majus. Mutation Research, 12, 381 .

haRRISON, B. J., AND CARPENETER, R. 1968. Fohn Innes Annual Report.

HAR RISON, B. J., AND GARPENTER, R. 1971. Fohn Innes Annual Report.

HARRISON, B. J., AND FINCHAM, J. R. s. 1964. Instability at the pal locus in Antirrhinum majus. 1. Effects of environment on frequencies of somatic and germinal mutation. Heredity, 19, 237.

HARRISON, B. J., AND FINGHAM, J. R. s. 1968. Instability at the pal locus in Antirrhinum majus. 3. A gene controlling mutation frequency. Heredity, 23, 67 .

MCGLINTOCK, B. 1951. Chromosome organisation and gene expression. Cold Spring Harb. Symp. Quant. Biol., 16, 13.

MCGLINTOCK, в. 1953. Induction of instability at selected loci in maize. Genetics, 38, 579. MGCLINTOCK, в. 1956. Controlling elements and the gene. Cold Spring Harb. Symp. Quant. Biol., 21, 197.

stUBBE, H. 1966. Genetik und Zytologie von Antirrhinum L., Sect. Antirrhinum. Fischer, Jena. STYLES, E. D. 1967. The metastable nature of paramutable $R$ alleles in maize. 2. Characteristics of alleles differing in geographic origin. Genetics, 55, 399.

STYLES, E. D., AND BRINK, R. A. 1969 . The metastable nature of paramutable $R$ alleles in maize. 4. Parallel enhancement of $R$ action in heterozygotes with $r$ and in hemizygotes. Genetics, 61,801 . 